\title{
Maximising the value of knowledge workers
}

\author{
P.D. Steyn \\ Centre for Information and Knowledge Management \\ University of Johannesburg \\ piet.steyn@eskom.co.za
}

\author{
A.S.A du Toit * \\ Centre for Information and Knowledge Management \\ University of Johannesburg \\ adutoit@uj.ac.za
}

This article focuses on the role of knowledge workers and their contribution to the achievement of an enterprise's objectives. Knowledge workers do not have enough time to keep abreast of new knowledge and need more than motivation to assist with the capturing of tacit knowledge. The purpose of the empirical survey was to determine the role and contribution of knowledge workers to the objectives of a South African technology-oriented company. A high percentage of respondents indicated a positive relationship between a worker's position on the organisational hierarchy and the opportunities for the worker to make knowledge contributions. The metrics applied to measuring the contribution of knowledge workers need to be considered carefully.

Key words: Knowledge workers, organisational hierarchy, productivity, case study

Received 20 March 2009; accepted March 2009

\section{Contents}

1. Introduction

2. Defining the knowledge worker

3. Nature of knowledge work

3.1 Knowledge practitioner

3.2 Knowledge engineer

3.3 Knowledge officer

4. Knowledge workers and productivity

5. Embedding knowledge into the knowledge worker's job outputs at a South African technology-oriented enterprise

5.1 Methodology

5.2 Research findings

6. Conclusion

7. References 


\section{Introduction}

Knowledge-worker productivity is one of the biggest $21^{\text {st }}$ century management challenges (Drucker 1999:92) and this requires major changes in attitude by the knowledge workers as well as management of an enterprise.

'In this period of unrest and rapid change, you can't successfully manage by being clever' (Drucker 2003:8). This statement by Drucker positions the knowledge worker in the enterprise. He refers to 'knowledge professionals' as workers who are considered key to the maintenance of market leadership in an enterprise. There is, however, a dichotomy in the social acceptance of the knowledge worker in today's business environment. Drucker argues that at present knowledge workers are retained via bonuses and other incentives. This will change, as the existing approach to short-term shareholder value will fall in disfavour with knowledge workers who will expect social recognition, satisfaction of their values and social power and will migrate into alliances or partnerships with business owners. This is a profound perspective of Drucker as it elevates the hierarchical position of the knowledge worker, implies the need for serious effort to measure the performance of the knowledge worker and commitment to ensure that the appropriate tools, both systems and support, are made available to maximise their contribution. The problem statement that is addressed in this article is: 'How can an enterprise assist to embed knowledge into a knowledge worker's job?' To solve this problem, the concept knowledge worker is defined and the nature of knowledge work, factors that influence knowledge worker behaviour and knowledge worker productivity are discussed.

\section{Defining the knowledge worker}

Gurteen (2006:1) defines the knowledge worker as: 'Those people who have taken responsibility for their work lives. They continually strive to understand the world about them and modify their work practices and behaviours to better meet their personal and organisational objectives. No one tells them what to do. They do not take "no" for an answer. They are self motivated.' According to Davenport (2005:3), knowledge workers are responsible for sparking innovation and growth in an enterprise. They invent new products and services, design marketing programmes and create strategies. Kelloway and Barling (2000:292) postulate the view that knowledge work is a 'discretionary behaviour focused on the use of knowledge' entailing four forms of knowledge work, which may or may not manifest itself at all hierarchical levels of the enterprise. These are:

- Creation of new knowledge or innovation

- Application of existing knowledge to current problems

- Packaging or teaching of knowledge

- Acquisition of existing knowledge via research and learning.

There are a number of approaches by authors such as Davenport (2005) and Nonaka and Takeuchi (1995) that attempt to define and classify knowledge workers according to a number of criteria. All of these taxonomies endeavour to attempt a classification as to what the particular distinguishing characteristics of a knowledge worker are, how these characteristics should be managed for improved performance and what is required from both the enterprise and the worker to optimise the achievement of mutually beneficial outcomes.

Gartner, Obermeier and Ramhorst (2002:168) refer to a classification employed by Siemens 
AG's Business Services Unit, the point of departure for their classification being that an employee may act as either a 'knowledge contributor' or a 'knowledge consumer' and that in fact both depend on the particular circumstances. This perspective originated in response to the unstructured fashion in which knowledge was exchanged, which required suitable approach and supporting technology to manage the exchange of knowledge. As an approach to manage this unstructured situation, the use of a 'knowledgemotion' portal was implemented. This portal allows for the exchange of information between contributors and consumers. The exchange process is similar to that of a marketplace. To ensure that the knowledge marketplace was functioning in a supportive manner, Siemens established the roles of 'knowledge manager' and 'knowledge broker' (Gartner et al. 2002:168) to facilitate and enhance the process of knowledge exchange.

In essence, however, all employees are knowledge brokers and if an environment conducive to knowledge sharing has been created, they will assist fellow workers with appropriate knowledge or direct them to a potential source thereof when requested to do so.

\section{Nature of knowledge work}

Efimova (2003:1) questions why little research has been done on trying to understand the actual work done by knowledge workers and how what they deliver can be improved. According to her a paradox arises as effort and investment are expended on technology, improving the flow of knowledge and the like and yet we do not know what knowledge work is. She postulates that this shortcoming or confusion is a result of the view that the outputs of a knowledge worker are 'discretionary and invisible' (Efimova 2003:1). She lists the following as sequential outputs of a knowledge worker:

- Locating, understanding and integrating information considered to be germane

- Leveraging social interaction to find new meaning and new knowledge

- Applying innovation to deliver new products and services.

According to Efimova (2003:1), 'such knowledge work is understood to comprise the creation of knowledge, the application of knowledge, the transmission of knowledge, and the acquisition of knowledge. Each of the activities is seen as discretionary behaviour. Employees are likely to engage in knowledge work to the extent that they have the (a) ability, (b) motivation, and (c) opportunity to do so.

Nonaka and Takeuchi (1995:151) employ the term 'knowledge-creating crew' and this is applied collectively to what they view as those who create knowledge in the 'knowledge creating company'. An important distinction is that a worker's hierarchical position is of less importance than the role that the person plays in terms of what knowledge the person imparts to the 'knowledge creating system' (Nonaka and Takeuchi 1995:151). However, this is a simplistic view in that from a reality perspective not all workers can provide the same degree of knowledge to the system in that they simply do not have equal opportunities to do so. The authors then introduce the concept of 'dynamic interaction' as the catalyst in the creation of knowledge, which is the result of such interaction between three sets of 'players'. The use of the term 'players' by the authors (Nonaka and Takeuchi 1995:151) is intentional, as they wish to move away from the impact which the traditional hierarchical organisational structure has on thinking about who creates and uses knowledge, hence a more distinctive classification, namely knowledge practitioners, knowledge engineers and knowledge officers. These three classes of workers constitute the knowledge-creating crew. Essentially Nonaka and Takeuchi create a paradox in their classification, as they apply a taxonomy that is based upon classical organisational hierarchical thinking. 
While these authors agree that knowledge is created everywhere and anywhere in the enterprise, in an attempt to demonstrate that there are types of knowledge workers creating different kinds of knowledge, they still revert to the classical organisational hierarchy to locate the creators of different knowledge.

The roles of the knowledge-creating crews as described by Nonaka and Takeuchi $(1995: 152)$ are:

- Knowledge practitioner, which has two complementary groups of workers:

○ Knowledge operators

$\circ$ Knowledge specialists

- Knowledge engineers

- Knowledge officers.

Nonaka and Takeuchi (1995:152) refer to knowledge practitioners and knowledge engineers, with the former's role described as the 'embodiment of knowledge'. The knowledge engineer is viewed as the link between senior management and the 'reality of the front line of business' (Nonaka and Takeuchi 1995:154).

\subsection{Knowledge practitioner}

Nonaka and Takeuchi (1995:152) state that the knowledge practitioner accumulates, updates and generates both tacit and explicit knowledge on a daily basis. These workers are in direct liaison with the external environment of the enterprise and have access to the most current externalities that have an impact or potential impact on the enterprise.

Nonaka and Takeuchi (1995:152) make a further distinction in the grouping of knowledge practitioners, that is the knowledge operator and the knowledge specialist. While both groups accumulate and generate knowledge, the major distinction is in the outputs, with the knowledge specialists employing a structured information-based and systems-related output and the knowledge operators engaging in the delivery of embodied skills and the related social interaction in the exchange of the concomitant knowledge.

\subsection{Knowledge engineer}

The knowledge engineer's role is to translate strategic vision into deliverables, leveraging the resources of the enterprise via the creation and the application of new knowledge (Nonaka and Takeuchi 1995:154). Knowledge gained from both management and front-line employees are merged and reproduced as explicit knowledge, suitably adapted to enhance new product and service development and deliverables. The role of the knowledge engineer is the management of the knowledge conversion process, as well as the management of the movement of knowledge across the various organisational levels.

For middle managers to be classified as knowledge engineers, Nonaka and Takeuchi (1995:156) state a number of personal and proficiency attributes that are pre-requisites for success:

- Project management ability

- Innovation

- Ability to integrate methodologies to produce new knowledge

- The use of metaphors/storytelling (narrative techniques) to enhance knowledge creation and generation

- Credibility and trust among peers

- Futuristic thinking leveraging past experience 


\subsection{Knowledge officer}

Knowledge officers articulate the vision of the enterprise at the highest level of the hierarchy. They are responsible for setting strategy and doing it in a manner that allows it to be translated from a conceptual stage to an executable stage via the knowledge engineers. It is of paramount importance that these officers demonstrate the value of knowledge management in the enterprise, whether via qualitative or quantitative criteria (Nonaka and Takeuchi 1995:157). The authors refer to a number of requirements that need to be met before a senior manager can be considered a knowledge officer. These are, inter alia, an ability to articulate the vision of the enterprise, demonstrated leadership and commitment in terms of knowledge requirements to assist the objectives of the enterprise and the ability to 'direct and manage the total process of organizational knowledge creation' (Nonaka and Takeuchi 1995:158).

\section{Knowledge workers and productivity}

Drucker (1999:84) lists six major factors that influence knowledge worker productivity:

- What is the knowledge worker's task?

o The crucial difference between the knowledge worker and the manual worker is considered to be the fact that contrary to the former, in the case of the latter the task is always given, and the worker is expected to perform it in the best possible manner.

- Another distinguishing factor is that the task per se is not as obvious as that of the manual worker. This is because a number of alternatives and appropriate decisions based upon prior knowledge may be required.

- The approach to defining the tasks also assists with the elimination of unnecessary tasks, which inhibit the knowledge worker's ability to perform.

○ Drucker (2000:9) introduces another approach by merely asking: 'What are you being paid for, and how much time do you spend doing that?'

- Knowledge workers should manage themselves and in order to do this they require autonomy. Effective enterprises have the capacity and ability to allow workers to be placed or place themselves in jobs where they can contribute most - this forms part of the shift towards worker self-management where workers believe that they are paid to be effective (Drucker 2000:10).

- Knowledge workers are required to be innovative on a continuous basis and must encapsulate this in their tasks and outputs.

- Continuous learning is required of the knowledge worker, as well as continuous teaching by the knowledge worker.

- Quality of output by the knowledge worker is as important as productivity.

- The knowledge worker's productivity needs to be assessed as an asset to the enterprise and not as a cost.

However, Efimova (2003:2) states that the difficulties in measuring knowledge work and the limited control which management can exercise over the activities of knowledge workers are responsible for the lack of focus on the knowledge worker in the enterprise. She ascribes this lack of focus to the difficulties in measuring their outputs, the fact that it is easier to measure specific contributions/projects than taking a macro-perspective and dealing with concomitant difficulty in measuring overall contribution to the enterprise. This view is not entirely correct. Davenport and Probst (2002:12) refer to comments by Von Pierer, then CEO and President of Siemens Aktiengesellschaft, Germany, that in the early 1990 s 50\% of the value added at Siemens came from knowledge-intensive products and services and that in 2002 this 
metric had increased to between 60 to $80 \%$ and was still growing.

When measuring specific projects and their contribution, Efimova (2003:2) postulates that the process of getting to the results does not necessarily fit the work practices of the individual knowledge worker who is regarded as an overhead rather than a bottom-line contributor.

The productiveness of a factor of production is measured by expressing the output achieved as ratio of the amount of input applied to produce it. This is a narrow view and does not take into consideration a number of issues that apply to knowledge work. Quality is of the essence in knowledge work and productivity only addresses it indirectly. Davenport (2005:46) relates this to how much people are prepared to pay for quality knowledge. He continues that the ability to define the outputs accurately is a pre-requisite. Lastly, according to Davenport (2005:47), there are factors that do not cost any more or less money, but in themselves will enhance knowledge work. An example is a physical environment or an enterprise culture that is conducive to knowledge sharing. A number of elements play a role in an endeavour to enhance the performance of knowledge workers. These initiatives relate to issues such as the physical environment of the worker, the technological support systems, training and so forth. Davenport argues that most enterprises that implemented programmes in this domain focused on worker behaviour change, whether via cultural aspects, worker role classification approaches or an extensive focus on communities of practice and the information and knowledge environments that support them (Davenport 2005:121).

Prior to taking steps or developing solutions to enhance worker performance, it is necessary to have a view on what the demands are that they are faced with and how they respond to them. Those workers, who according to Davenport's (2005:133) research had mastered their information and knowledge issues, took a number of steps, the common attributes of which were:

- The use of a few key tools and the avoidance of gimmicks and fancy software, although there was some experimentation with newer applications

- Use of more than one device was limited, that is only one laptop with few other devices such as interfacing palmtops

- Information was periodically organised in terms of some set methodology and priority chosen by the worker

- The workers did not advertise their knowledge, but did assist when requested

- The workers had a quest for new knowledge and were prepared to ask for assistance in gaining this

- Assistants were used, but not in all instances

- There was no ubiquitous use of the so-called electronic office - some degree of the use of paper was prevalent.

Davenport $(2005: 165)$ states that while a lot is said about the potential impact of physical infrastructure on knowledge worker performance, very little has been done about it. He refers to previous research, supported by logic, indicating that there are a number of known issues. These are:

- Knowledge workers prefer closed offices as it enhances concentration, but also prefer to be able to communicate with fellow workers in an informal manner from their offices. This suggests some arrangement using semi-high walled offices, with noisecancelling equipment installed to reduce the impact of banter and loud telephone conversations, the emphasis being that informal interaction needs to be promoted and yet the ability to concentrate and work in a semi-private environment needs to be respected. 
- Knowledge workers congregate in certain geographical areas; an example is Silicon Valley, and Boston for academics. The issue is that 'one goes where the action is'.

- Knowledge workers are by nature mobile, spending considerable time in discussions away from the office. This implies that they need to be connected, for example by the use of $3 \mathrm{G}$ cards, laptop computers or dial-in access from a number of off-site locations, to enable them to continue networking. Knowledge worker networks and their physical surroundings, including support infrastructure such as intranets, must facilitate this behaviour.

- Knowledge workers who are required to be in constant interaction with one another must be physically located as closely as possible.

- Knowledge workers do not really care for fancy or sophisticated avant-garde office infrastructure; they are more concerned that what is there allows them to do what they need to do at a specific time.

An understanding of the classification, role and nature of the knowledge workers is a prerequisite to leveraging both the tacit and explicit knowledge available and developed in the enterprise. It is evident that the knowledge worker's contribution to the enterprise can be enhanced via the application of communities of practice, physical surroundings which are conducive to social interaction, metrics to enhance worker performance and recognising that the management of knowledge workers requires a paradigm shift in terms of conventional worker management approaches.

\section{Embedding knowledge into the knowledge worker's job outputs at a South African technology-oriented enterprise}

\subsection{Methodology}

The purpose of the empirical survey was to determine to what degree the South African enterprise could assist to embed knowledge into the knowledge worker's job outputs. The enterprise, an electricity utility, can be described as a technology-oriented enterprise with emphasis on the quality of electricity supply, the concomitant development of its employees and a corporate desire to remain at the forefront of many areas of the electricity energy business, for example cost of generation, safety and development of appropriate as well as cutting edge technology, and to this end has innovation as one of its core corporate values. In 2006 the enterprise employed 30000 employees and had an annual turnover of R36 307 million.

In total 355 employees were randomly selected to form the sample of this study. A questionnaire was compiled using the research by Ruggles (1998), Carrillo, Robinson, AlGhassani and Anumba (2004), Sarnoff and Winner (2003), and Jacobson and Prusak (2006). From this research, questions were identified that covered the characteristics of knowledge work, as well as aspects that influence knowledge work behaviour and increase knowledge work productivity. A draft questionnaire was given to a number of respondents for comment as to their understanding of the questions, length of the questionnaire in terms of time required to complete it and ease of returning the completed response via e-mail. The questionnaire was e-mailed on 4 October 2007 and the 355 respondents were given until 14 October 2007 to respond. A follow-up exercise was conducted on non-respondents in an endeavour to improve the response rate. Of the 355 addresses on the list, 16 were returned as undeliverable, with reasons ranging from the contact being on leave to the employee having recently left the enterprise, leading to the suspension of the user's e-mail address for security reasons in terms of company policy. Eight questionnaires were also physically handed to employees for completion. Thus $363(355+8)$ questionnaires were distributed and 16 
requests were not responded to for valid reasons, yielding 347 (363 - 16) valid questionnaires issued. A hundred and twenty-two questionnaires were completed and returned in time, which represents a response rate of $36,16 \%$.

All responses received were collated centrally and forwarded to the Statistical Consultation Service Department at the University of Johannesburg for further analysis, using the SPSS software package.

\subsection{Research findings}

The credibility of the research was measured by the Cronbach Alpha Coefficient and the scale employed was $0 \%$ to $100 \%$, with the higher percentage indicating a higher credibility rating. The individual sets of questions in the research questionnaire were rated as per Table 1. An overall coefficient of $78,7 \%$ was calculated for the results obtained and this is considered to be in the range of scores considered as being reliable.

Table 1 Reliability statistics employing Cronbach's Alpha

\begin{tabular}{|l|l|l|l|}
\hline $\begin{array}{l}\text { Question } \\
\text { (s) }\end{array}$ & $\begin{array}{l}\text { Cronbach's } \\
\text { Alpha }\end{array}$ & $\begin{array}{l}\text { Cronbach's } \\
\text { Alpha based } \\
\text { on } \\
\text { standardised } \\
\text { items }\end{array}$ & $\begin{array}{l}\text { No } \\
\text { of } \\
\text { items }\end{array}$ \\
\hline $1 \mathrm{a}-2 \mathrm{a}$ & 0,653 & 0,654 & 2 \\
\hline $1 \mathrm{~b}-2 \mathrm{~b}$ & 0,342 & 0,343 & 2 \\
\hline $1 \mathrm{c}-19 \mathrm{c}$ & 0,751 & 0,753 & 18 \\
\hline $1 \mathrm{~d}-2 \mathrm{~d}$ & 0,237 & 0,244 & 2 \\
\hline $1 \mathrm{e}-16 \mathrm{e}$ & 0,802 & 0,780 & 16 \\
\hline $1 \mathrm{f}-22 \mathrm{f}$ & 0,619 & 0,662 & 22 \\
\hline All & 0,787 & 0,783 & 63 \\
\hline
\end{tabular}

\subsubsection{Qualification group representation}

The views and attitudes of the respondents needed to be measured and interpreted in terms of their formal qualifications, especially in the lower age groups, as the potential impact of 'job drift' will not be as marked as in the two highest age groups. The inference is also that the respondents in the higher levels of education required more research and exposure to information and knowledge on a wider basis to achieve their qualification(s) than, for example, a respondent with only a matriculation (M) qualification. The views of the more highly qualified respondents are thus invaluable in structuring any initiative in terms of measuring the contribution of knowledge workers. Figure 1 illustrates the frequency distribution of respondents in this category.

A higher frequency of respondents with an 'M + 3' qualification is to be expected in a high technology and capital-intensive enterprise.

Figure 1 Research questionnaire respondents: frequency distribution of questionnaires completed per qualification group 


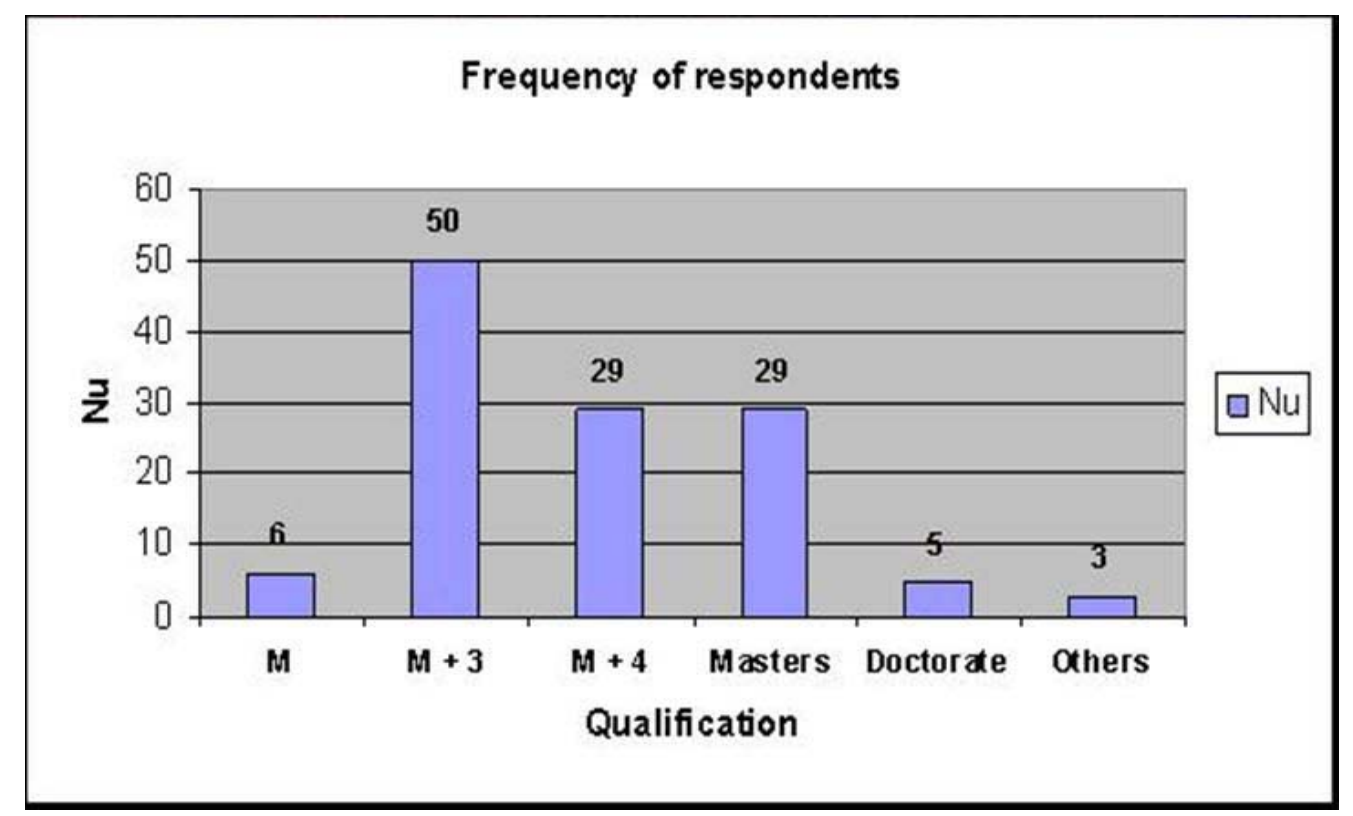

\subsubsection{Knowledge contribution and hierarchical position}

Respondents were asked to what extent they agreed with the statement that the knowledge contribution of a worker may be as a result of his or her position in the organisational hierarchy, those in higher positions thus having greater opportunities than lower-down employees.

More than $84 \%$ of the respondents were of the opinion that a worker's hierarchical position contributed to the opportunity the worker had of making knowledge contributions (see Figure 2). This opinion must be viewed in relation to the perception that the higher an employee is on the 'organisational ladder' the more knowledgeable that employee is and thus the greater his or her contribution. There is general consensus among the respondents that a knowledge worker's position in the organisational hierarchy does benefit that person's opportunities to make knowledge contributions. This is a perception that will need to be managed and hence the requirement that the importance of knowledge work must be demonstrated and acknowledged by senior management.

Figure 2 Hierarchical position of a worker and knowledge contribution - percentage distribution 


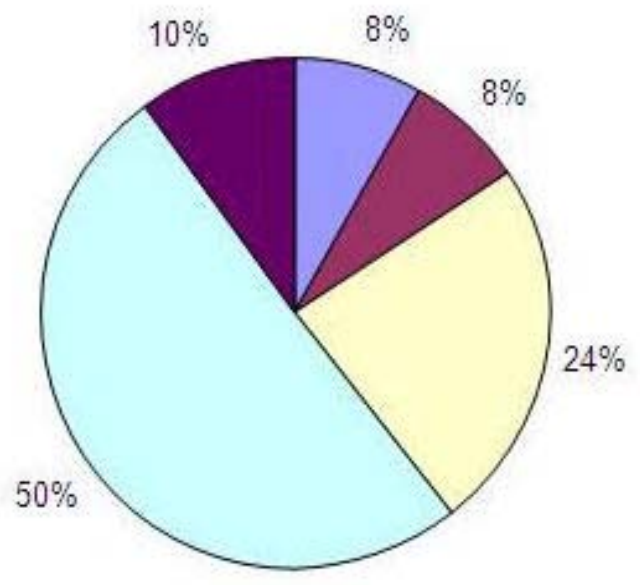

\begin{tabular}{|l|}
\hline$\square$ Not at all \\
$\square$ Very little \\
$\square$ Somewhat \\
$\square$ Great extent \\
$\square$ Very great extent
\end{tabular}

\subsubsection{Measuring the productivity of a knowledge worker}

This question required the respondent to make a clear decision on how he or she should be reviewed in terms of performance as a knowledge worker. Does the respondent prefer a formal approach such as the Balanced Score Card or a more socially oriented approach such as a peer review? Both approaches have advantages and disadvantages, depending on the individual's predisposition to the methodology and the reviewers involved. However, if the contribution of knowledge management to the enterprise's bottom line cannot be measured easily, a knowledge worker cannot be expected to accept readily a highly formalised approach such as the Balanced Score Card review being applied. The respondents indicated that they prefer the peer review approach (see Figure 3). In terms of categories 'Great extent' and 'Very great extent', $76 \%$ of the population indicated this as their preference.

Figure 3 Preference for a peer review process rather that a Balance Score Card process for measuring productivity

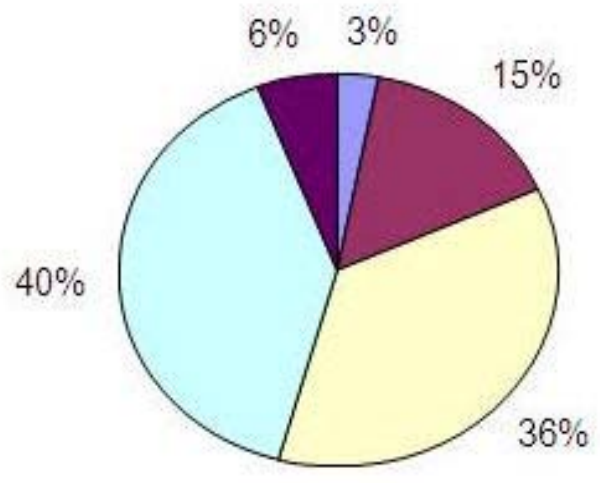

$$
\begin{aligned}
& \square \text { Not at all } \\
& \square \text { Very little } \\
& \square \text { Somewhat } \\
& \square \text { Great extent } \\
& \square \text { Very great extent }
\end{aligned}
$$


There is a tendency for the older age groups to prefer the peer review process. The percentage scores, combined, for the two categories 'Great extent' and 'Very great extent' are respectively $71 \%, 44 \%$ and $55 \%$ for the age groups 30 to 39 years, 40 to 49 years and 50 to 59 years. It is the researchers' opinion that these age groups are more comfortable being evaluated by peers rather than via a systems-based review process over which they cannot exert any 'social' control. This will need to be kept in mind when designing performance review approaches for knowledge workers, as a worker who is of the opinion that the performance management approach is unfair or biased will not perform as required.

\subsubsection{Knowledge interaction and time spent thereon}

Respondents were asked questions on how they spent their working time; these questions were based upon research done by Jacobson and Prusak (2006) (see Figure 4).

Figure 4 Views on knowledge interaction and time spent thereon

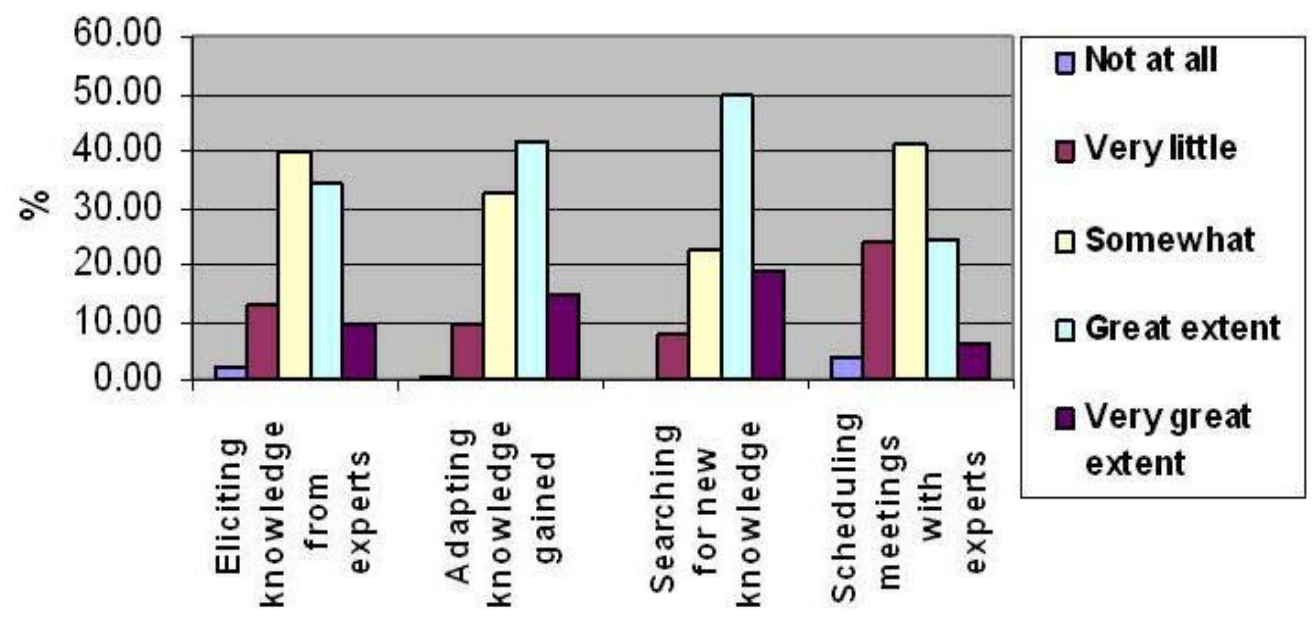

The analysis reflects that time spent on knowledge interactions by the respondents is ranked, firstly, relating to searching for new knowledge, secondly, adapting knowledge gained and, thirdly, eliciting knowledge from experts. This is very different from the results of the research done by Jacobson and Prusak (2006), which indicates that most time was spent on adapting knowledge gained, less on eliciting knowledge from experts and then still less on searching for new knowledge. It is deduced that knowledge is currently not managed effectively in the enterprise and that knowledge workers waste time searching for new knowledge.

\subsubsection{Views on dissatisfaction with knowledge and knowledge culture}

Respondents were required to express a view on the applicability of four variables to their present work situation. Figure 5 indicates the results in terms of each of the variables as listed by Pollard (2004).

Figure 5 Views on dissatisfaction with concepts of managing knowledge and knowledge culture 


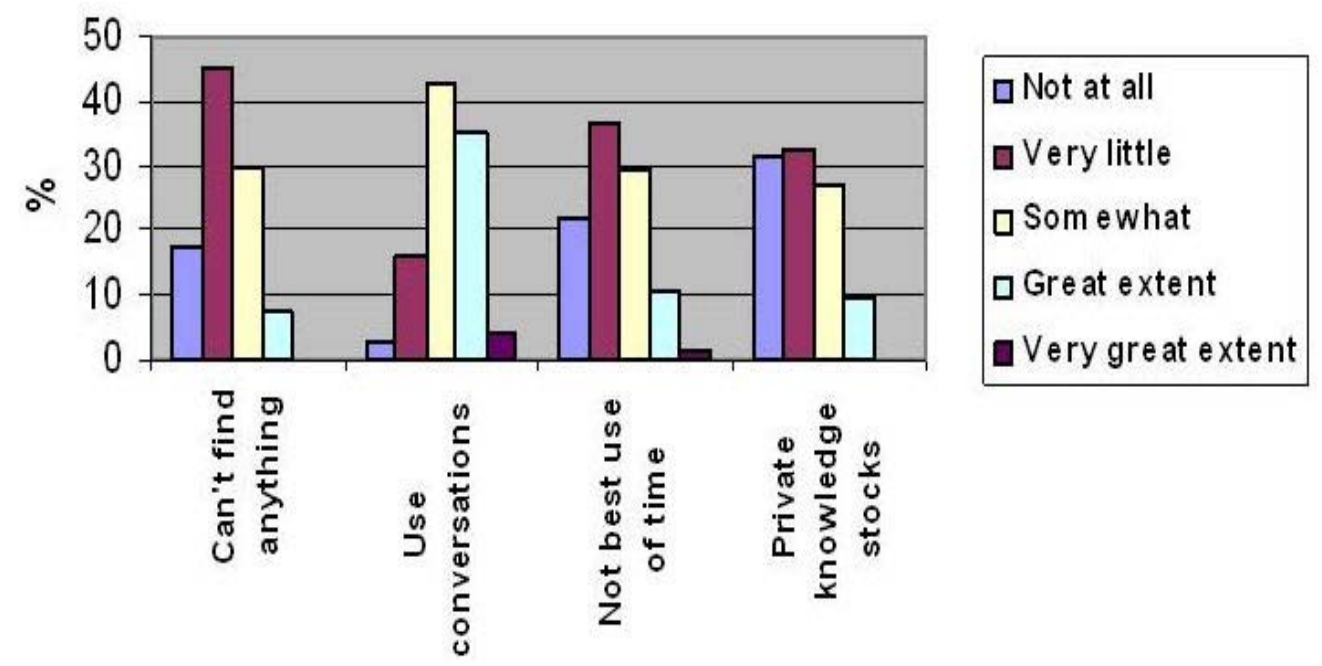

In terms of the specific variables, the following applies to the results obtained from the respondents:

- 'I can't find anything': The greater number of scores was in the categories 'Very little', $54(45 \%)$, and 'Somewhat', 36 (30\%), out of 120 valid responses, indicating that the statement was not applicable to the majority of respondents.

- 'I get what I need more effectively from conversations': There was a tendency towards a higher degree of agreement with the statement; the scores were, respectively, in the categories 'Somewhat' 51 (43\%), and 'Great extent' 42 (35\%), out of 120 valid responses. The views given support the potential for increasing the extent of application for narrative approaches as they reflect an orientation towards the use of conversation per se.

- 'Knowledge gathering is not the best use of my time': There was disagreement from the respondents as to this statement with the majority of the responses reflecting views of 'Not at all', 26 (22\%), 'Very little', 44 (37\%), and 'Somewhat', 35 (29\%), out of 120 valid responses.

- 'I prefer private knowledge stocks that I won't share with others because I don't trust them enough': The responses reflected a willingness to share private knowledge stocks and were encouraging from a knowledge transfer perspective. The results obtained reflect the following results: 'Not at all', 37 (31\%), 'Very little' 38 (32\%), and 'Somewhat', 32 (27\%), out of 120 valid responses.

The results obtained were encouraging in that they did not present major obstacles in terms of the attitudes of the knowledge workers to the variables encountered by Pollard (2004). The willingness to share private knowledge stock was very encouraging, as was the response to using conversations as an approach to obtain the required knowledge.

\section{Conclusion}

In this article, the nature of knowledge work and the factors that influence knowledge worker behaviour and knowledge worker productivity are discussed. An empirical survey was 
conducted to determine whether a technology-oriented enterprise was successful in embedding knowledge into its knowledge workers' jobs. It was concluded that the enterprise was not really geared to future knowledge demand and that the knowledge workers were sensitive to this shortcoming. A comparative analysis was done on the time spent by knowledge workers on specific knowledge interactions and the results indicated that, except for the ranking of the activities, the same activities had similar levels of importance in this research study as in that done by two US researchers.

A very high percentage of respondents indicated a positive relationship between a worker's position on the organisational hierarchy and opportunities for the worker to make knowledge contributions. This is a fallacy which needs to be addressed if any knowledge management initiative is to be successfully deployed in the enterprise.

The metrics applied to measuring the contribution of knowledge workers need to be considered carefully, as a formal approach such as the Balanced Score Card review may be too formal in an environment where there is considerable disagreement in general about appropriate metrics for measuring performance and bottom-line contribution. While the peer review process was indicated by the respondents to be the preferred method, it does have inherent disadvantages due to the social nature of the review and the bias which this may introduce into the evaluation in view of personal issues.

The respondents indicated that in terms of time spent the highest demand was created by searching for new knowledge, then by adapting knowledge gained and then by eliciting knowledge from experts. The importance of knowledge work and the management of knowledge should be demonstrated and acknowledged by senior management of the enterprise and an infrastructure to manage knowledge successfully should be implemented.

\section{top}

\section{References}

Carrillo, P., Robinson, H., Al-Ghassani, A. and Anumba, C. 2004. Knowledge management in UK construction: strategies, resources and barriers. Project Management Journal 35 (1):46-56.

Davenport, T.H. 2005. Thinking for a living. Boston: Harvard Business School Press.

Davenport, T.H. and Probst, G.J.B. 2002. Siemens' knowledge journey. In: Davenport, T.H. and Probst, G.J.B. (eds.) Knowledge management case book: best practices. $2^{\text {nd }}$ ed. Erlangen: Publicis, KommunikationsAgentur GWA.

Drucker, P.F. 1999. Knowledge-worker productivity: the biggest challenge. California Management Review 41(2):79-94.

Drucker, P.F. 2000. Managing knowledge means managing oneself. New York: John Wiley \& Sons, Inc.

Drucker, P.F. 2003. New trends in management: go with the flow or fail. Executive Excellence 20(8):8-9.

Efimova, L. 2003. Knowledge worker paradox. The Knowledge Board. [Online]. https://doc.telin.nl/dsweb/Get/Document-35469/. (Accessed 15 September 2007). 
Gartner, T., Obermeier, H. and Ramhorst, D. 2002. A guided tour through knowledgemotion ${ }^{\mathrm{TM}}$ : The Siemens Business Services Knowledge Management Framework. In:

Davenport, T.H. and Probst, G.J.B. (eds.) Knowledge management case book: best practices. $2^{\text {nd }}$ ed. Erlangen: Publicis, KommunikationsAgentur GWA.

Gurteen, D. 2006. The Gurteen perspective: taking responsibility. Inside Knowledge 10 (1):1-2.

Jacobson, A. and Prusak, L. 2006. The cost of knowledge. Harvard Business Review 84 (11):34.

Kelloway, E.K. and Barling, J. 2000. Knowledge work as organizational behavior. International Journal of Management Reviews 2(3):287-304.

Nonaka, I. and Takeuchi, H. 1995. The knowledge-creating company. Oxford: Oxford University Press.

Pollard, D. 2004. What do knowledge workers want? Global Knowledge Review September 2004:4-5.

Ruggles, R. 1998. The state of the notion: knowledge management in practice. California Management Review 40(3):80-89.

Sarnoff, A. and Winner, T. 2003. Knowledge management and intranet: putting people first. [Online]. http://www.intranetjournal.com/articles/200304/pij_04_23 03b.html. (Accessed 5 August 2007). 